\title{
The effect of presence of family members on the anxiety level of candidates for esophagogastroduodenoscopy: A randomized controlled trial
}

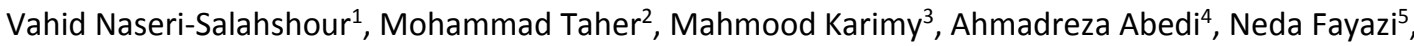 \\ Mahbobeh Sajadi ${ }^{*}$, Hamid Abredari ${ }^{7}$
}

Received: 12 Sep 2017

Published: 29 Jun 2019

\section{Abstract}

Background: Anxiety and its control is a public health problem worldwide. This study was conducted to determine the effect of family members' presence on the anxiety level of patients who were candidates for esophagogastroduodenoscopy (EGD).

Methods: This randomized controlled trial study was performed in Shahid Chamran hospital in city of Saveh in IR Iran. In this study, 96 patients who were candidates for EGD and met the inclusion criteria were assigned into control and intervention groups by simple random sampling method. The demographic questionnaire and Spiel Berger's State and Trait Anxiety Questionnaire (STAI) were used to measure anxiety.

Results: No significant difference was found between the 2 groups in the mean level of anxiety before intervention $(p=0.13)$. After intervention, the level of anxiety decreased significantly in the intervention group ( $p=0.001)$. However, the mean level of anxiety was not significant in the control group after intervention $(\mathrm{p}=0.09)$.

Conclusion: The results of the present study showed that the presence of family members during endoscopy may reduce the patient's anxiety level, and thus it is recommended as a non-pharmaceutical, beneficial, and safe intervention.

Keywords: Anxiety, Family member, Esophagogastroduodenoscopy, Clinical trial

Conflicts of Interest: None declared

Funding: Saveh University of Medical Sciences

\section{*This work has been published under CC BY-NC-SA 1.0 license. \\ Copyright $₫$ Iran University of Medical Sciences}

Cite this article as: Naseri-Salahshour V, Taher M, Karimy M, Abedi A, Fayazi N, Sajadi M, Abredari H. The effect of presence of family members on the anxiety level of candidates for esophagogastroduodenoscopy: A randomized controlled trial. Med J Islam Repub Iran. 2019 (29 Jun);33:62. https://doi.org/10.47176/mjiri.33.62

\section{Introduction}

Chronic diseases are increasingly developing due to changes in life style and industrialization of communities, particularly in developed countries, and they are considered as one of the main problems in the health systems of countries (1). Gastrointestinal disease is also a chronic disease $(2,3)$. The complex nature and misguiding symptoms of digestive diseases have made it necessary to discover new diagnostic methods and update the available

Corresponding author: Dr Mahbobeh Sajadi, m.sajadi@arakmu.ac.ir

1. Medical-Surgical Nursing Department, School of Nursing, Arak University of Medical Sciences, Arak, Iran

2. Medical-Surgical Nursing Department, School of Nursing and Midwifery, Saveh University of Medical Sciences, Saveh, Iran

3. Social Determinants of Health Research Center, Saveh University of Medical Sciences, Saveh, Iran

4. Traditional and Complementary Medicine Research Center (TCMRC), MedicalSurgical Nursing Department, School of Nursing, Arak University of Medical Sciences, Arak, Iran

5. Critical Care Nursing Department, School of Nursing and Midwifery, Saveh University of Medical Sciences, Saveh, Iran

6. Pediatrics Nursing Department, School of Nursing, Arak University of Medical Sciences, Arak, Iran

7. Medical-Surgical Nursing Department, School of Nursing and Midwifery, Iran University of Medical Sciences, Tehran, Iran methods (4). Some of these diagnostic methods, such as endoscopy, are invasive and expose the patient to a high rate of anxiety (5-8). Endoscopy is a non-surgical method used to study different parts of gastrointestinal system (9, 10). EGD is one endoscopic method and an important tool for examining the upper channel of digestive system. This diagnostic-therapeutic procedure is used frequently in clinical investigations and has many apparent diagnostic

$\uparrow$ What is "already known" in this topic:

Anxiety and its related problems are known as a common disorder and affect all aspects of a person's life. Anxiety leads to an undesirable condition and affects quality of life.

$\rightarrow$ What this article adds:

Since anxiety is significantly associated with physiological and psychological health and quality of life, its management with noninvasive methods, such as family member's presence during diagnostical and therapeutical procedures, may help reduce the anxiety level of patients during EGD. 
advantages and therapeutic applications (11-14). In this technique, a flexible endoscope is directed into gastric and duodenum organs through the throat to examine the upper part of the digestive system (15). EGD is a fast and safe procedure and can be performed without using sedatives; however, it causes a sever anxiety and creates a feeling of exposure to damaged and unsafe conditions, as well as shame and inconvenience in patients $(16,17)$. Feeling of anxiety is not normal but necessary for survival; however, when severe anxiety occurs and negatively affects activities of daily living, it is considered as a disorder (18-20).

Previous studies have shown that anxiety level is high of before endoscopy (19). High anxiety can cause many problems for the patients, their family, and the treatment team. It may also complicate the procedure due to using excessive sedation (19), $(21,22)$. In fact, endoscopy can cause such anxiety in a person that could result in patient's avoiding the procedure (23). The anxiety caused by endoscopy will prolong the endoscopic procedure and increase its side effect. Thus, reducing anxiety is significantly important (9). Eliminating anxiety can ease the process and help physicians perform endoscopy more conveniently $(24,25)$. Medicinal or nonmedicinal methods can be used to reduce and control anxiety (26). Medicines such as benzodiazepines, serotonin reabsorb inhibitors, narcotics, opioid medicines, and triple ring antidepression drugs are used to reduce anxiety (27). However, using sedatives is not free of side effects; for example, it increases the patient's medical expenditures $30 \%$ to $50 \%$ and increases the health care staff's work to relieve, improve, and control the disease $(28,29)$. Considering the industrialization of modern communities and the increase in the rate of chronic diseases, the need for using diagnostic procedures, such as endoscopy and colonoscopy, is increasing progressively $(4,30,31)$. Thus, it is necessary to use noninvasive and nonmedicinal methods to reduce the anxiety and discomfort of patients (32).

The tendency to use nonmedicinal methods is on the rise and presence of one of the family members while the patient undergoes EGD is of great importance. The performed studies on this subject imply that the family members' presence reduces the feeling of pain while the patient undergoes EGD (33). Considering the studies conducted on the high prevalence of anxiety before endoscopy (19), the aim of this study was to determine the effectiveness of family member's presence on the anxiety level of the patient while the patient underwent EGD.

\section{Methods}

Study design and main inclusion and exclusion criteria

This was a double-blind randomized controlled trial conducted in Chamran Martyr hospital in city of Saveh, Iran, during February 2015 and April 2016. The study population included the patients who were candidates for EGD. The main inclusion criteria were as follow: willingness to participate in the study; prescription of endoscopy; and no participation in any problem solving training courses, critical thinking, emotional intelligence, and methods of stress control and Yuga in the past 6 months. Incompleteness of questionnaires, recognizing mental disorder in participants during the study and withdrawing from the study were considered as exclusion criteria.

\section{Sample size and data collection}

In this study, 96 patients were selected through purposebased method and randomly divided into intervention $(n=48)$ and control $(n=48)$ groups $(34)$.

Both groups were homogenized to minimize the intervening parameters, such as age, sex, and study level, and marital status. The participants were entered the study according to Consolidated Standards of Reporting Trials (CONSORT) guideline and were randomly placed into 2 intervention and control groups (35) (Fig. 1).

\section{Instruments}

The data gathering tools included demographic questionnaire (age, sex, and level of education, marital status, job status, and other additional information) and Spiel Berger's State and Trait Anxiety Inventory (STAI). STAI scoring is based on likert (1 to 4) scale and the sum of scores in any part ranges from 20 to 80 . STAI has a high scientific validity and is considered as a standard tool for evaluation of anxiety; its scientific validity and reliability were evaluated by Khodayarifard et al. (36). STAI includes separated self-measuring scales for measuring state anxiety (Twenty sentences that evaluate the person's feelings at the moment) and trait anxiety (Twenty sentences that evaluate general feelings).

\section{Intervention}

The demographic questionnaire was completed by patients. The intervention group filled out State Anxiety Questionnaire accurately before the endoscopy procedure and at the presence of one of their family members. The control group filled out the Anxiety Questionnaire before the endoscopy procedure without the presence of their family member. Trait Anxiety Questionnaire was filled out by both groups 2 days after the endoscopy procedure at the hospital.

\section{Ethical considerations}

This study was registered in Iranian Registry of Clinical Trials [IRCT2017011931522N2] and was approved by the Ethics Committee of Saveh University of Medical Sciences [IR.SAVEHUMS.REC.1394.29].

\section{Statistical analyses}

Data were analyzed using SPSS 16 software for both descriptive and analytical statistics. For descriptive statistics, mean and standard deviation were used; and for analytical statistics, unilateral variance analysis, Fisher meth$\mathrm{od}, \mathrm{K}^{2}$, independent $\mathrm{t}$ test, and paired test were used. Significance level was set at 0.05 .

\section{Results}

The demographic information of the participants showed that most participants aged 41-48 years and that most of them were male and married (Table 1). Results of this study showed that the state anxiety level of the patients significantly decreased at the presence of a family 


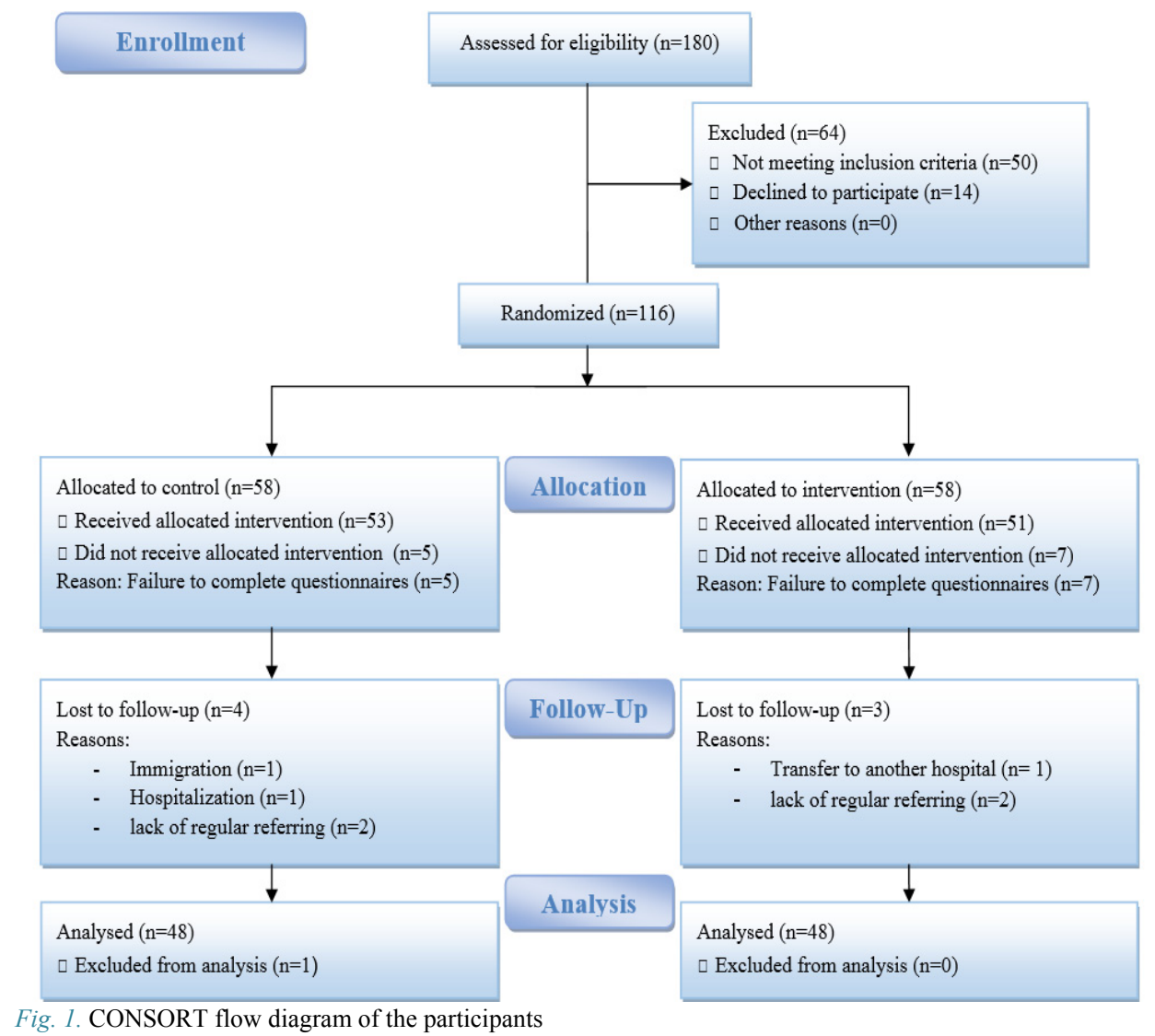

member during endoscopy in the intervention group $(p=0.001)$. However, the level of trait anxiety was not significantly different between the intervention $(p=0.08)$ and control $(\mathrm{p}=0.09)$ groups before and after the intervention (Table 2). According to the results of this study, the level of the state anxiety was decreased among the participants of the intervention group compared to those in the control group. Nevertheless, level of trait anxiety did not show any sign of change between the 2 groups.

\section{Discussion}

The present study showed that presence of a family member could reduce the patient's anxiety during endoscopy. Medicinal and nonmedicinal methods are available to reduce patients' anxiety (37). Nowadays, the tendency to use nonmedicinal methods to relieve the pain and anxiety is increasing. Several studies have been performed on the influence of different methods to reduce the patients' anxiety before and during endoscopy of upper part of the digestive system and have reported different results. For

Table 1. Demographic characteristics of participants

\begin{tabular}{|c|c|c|c|c|}
\hline \multirow[t]{2}{*}{ Variable } & \multicolumn{2}{|c|}{ Groups } & \multirow[t]{2}{*}{$\mathrm{p}$} & \multirow[t]{2}{*}{ Statistical test } \\
\hline & Control & Intervention & & \\
\hline Age (year) & $54.21 \pm 19.26$ & $49.95 \pm 19.34$ & 0.38 & t-test \\
\hline Sex & (\%) Frequency & (\%) Frequency & 0.60 & $X^{2}$ \\
\hline Male & $(54.2 \%) 26$ & $(52.1 \%) 25$ & & \\
\hline Female & $(45.8 \%) 22$ & $(47.9 \%) 23$ & & \\
\hline \multicolumn{5}{|l|}{ Marital status } \\
\hline Married & $(56.2 \%) 27$ & $(60.4 \%) 29$ & 0.13 & $X^{2}$ \\
\hline Single & $(43.7 \%) 21$ & $(39.5 \%) 19$ & & \\
\hline \multicolumn{5}{|l|}{ Level of education } \\
\hline Primary education & $(66.6 \%) 32$ & $(66.6 \%) 32$ & 0.25 & $X^{2}$ \\
\hline High school degree & $(20.8 \%) 10$ & $(18.7 \%) 9$ & & \\
\hline Academic degree & $(16.6 \%) 8$ & $(14.5 \%) 7$ & & \\
\hline \multirow[t]{2}{*}{ Group } & Before intervention & After intervention & $\mathrm{p}$ & Statistical test \\
\hline & Mean \pm SD & Mean \pm SD & & \\
\hline \multicolumn{5}{|l|}{ State anxiety } \\
\hline Intervention group & $42.1 \pm 3.75$ & $34.2 \pm 3.14$ & 0.001 & Pair t-test \\
\hline Control group & $41.08 \pm 4.10$ & $42.52 \pm 4.47$ & 0.09 & Pair t-test \\
\hline \multicolumn{5}{|l|}{ Trait anxiety } \\
\hline Intervention group & $39.1 \pm 3.75$ & $38.24 \pm 3.14$ & 0.08 & Pair t-test \\
\hline Control group & $38.07 \pm 4.10$ & $39.52 \pm 4.47$ & 0.09 & Pair t-test \\
\hline
\end{tabular}


instance, Eberhardt et al., in their study, entitled, "Information, social support and anxiety before endoscopy of upper part of digestive system" concluded that offering clear information and social support could reduce anxiety in patients before endoscopy (38). Callagan et al., in their study, entitled, "Effect of visual band or written information on patients candidates for endoscopy" found that offering visual information before endoscopy can reduce anxiety in patients (39). Maguire et al., in their study, "Effect of Cognitive and Behavioral Training on Patient's Candidates for Endoscopy" found that offering cognitive and behavioral information before implementation of endoscopy can reduce anxiety in patients (18). Furthermore, Kutluturkan et al. revealed that providing written information about endoscopy can reduce patients' anxiety before the procedure (14). The results of Pehlivan et al. study showed that providing verbal information to patients before implementing the endoscopy procedure has a positive effect on perception, acceptance, and reducing anxiety in these patients (40). Moreover, in Ju-Yeon et al. study, it was shown that preparing patients before endoscopy can significantly reduce their discomfort. Therefore, distracting the patients from the procedure by contact therapy, providing information, observing the endoscopy procedure by patient, Therapeutic relationship between patient and physician, perfume therapy, and listening to music during endoscopy can reduce patients' anxiety $(23,33)$. In Stanmore's study, it was found that training before endoscopy and listening to music during endoscopy can prevent the increase of diastolic pressure (41). The results of this study on the role of training are in line with previous studies. Maguire et al. concluded that providing information alone can reduce anxiety more than providing information and behavioral training. The results of the present study showed that presence of a family member while the patient is undergoing diagnostic procedures can reduce the patient's anxiety and discomfort. The limitation of this study was that it was performed in one medical center in city of Saveh. Thus, conducting similar studies with larger sample size and multicentral approach is highly recommended.

\section{Conclusion}

Patients' candidates for endoscopy experience a high rate of anxiety and based on the findings of previous studies, the presence of family members can be considered a nonmedicinal, beneficial, and effective method to reduce the patient's anxiety before undergoing any invasive therapeutic procedure.

\section{Acknowledgments}

This study was the result of a research project that was approved by Saveh University of Medical Sciences. Finally, authors express their appreciation and gratitude to the Vice Chancellor for Research of Saveh University of Medical Sciences, the honorable masters of Nursing and Midwifery School, nurses, and all patients' candidates for EGD in Shahid Chamran hospital in Saveh (Iran) who helped us to conduct this study.
Conflict of Interests

The authors declare that they have no competing interests.

\section{References}

1. Rana S, Kumar S, Rathore N, Padwad Y, Bhushana S. Nutrigenomics and its Impact on Life Style Associated Metabolic Diseases. Curr Genomics. 2016;17(3):261-78.

2. Heidari M, Shahbazi S. Effect of Quran and music on anxiety in patients during endoscopy. J Know Health. 2013;8(2): 67-70.

3. Kord Tamini B, Lashani I, Akbarifar S. Group Training of Spiritual Positivism on Reduction of the Symptoms of Depression, Anxiety, and Stress in Prisoners. Health Scope. 2017;6(1): e37200.

4. Ivanov A. Barriers to the Introduction of New Medical Diagnostic Tests. Lab Med. 2013;44(4):e132-e6.

5. Arzani A, Lotfi M, Abedi A. Experiences and Clinical Decisionmaking of Operating Room Nurses Based on Benner's Theory. JBUMS. 2016;18(4):35-40.

6. El-Gilany AH, Amr M, Hammad S. Perceived stress among male medical students in Egypt and Saudi Arabia: effect of sociodemographic factors. Ann Saudi Med. 2008;28(6):442-8.

7. Kim SM, Mayassi T, Jabri B. Best Practice \& Research Clinical Gastroenterology. Best Pract Res Clin Gastroenterol. 2015;29(42):5e435.

8. NikbakhtNasrabadi A, Bakhshayeshi O, Parsayekta Z, Hoseyni M, Taghavi T, Rezvani H. The effectiveness of implementing nursing consultation on the anxiety of patients undergoing GI endoscopy. IJN. 2012;25(79):54-62

9. Nguyen VX, Le Nguyen VT, Nguyen CC. Appropriate use of endoscopy in the diagnosis and treatment of gastrointestinal diseases: up-to-date indications for primary care providers. Int J Gen Med. 2010;3:345.

10. Vargo JJ, Cohen LB, Rex DK, Kwo PY. Position statement: nonanesthesiologist administration of propofol for GI endoscopy. Hepatology. 2009;50(6):1683-9.

11. Adler DG, Siddiqui AA. Endoscopic management of esophageal strictures. Gastrointestinal Endoscopy. 2017.

12. Chang KC, Chen WM, Wei KL. Endoscopic treatment of Bouverets syndrome in an extremely elderly patient with Holmium: YAG laser. Ann Saudi Med. 2016;36(6):436-9.

13. Cotton PB, Williams CB. Practical gastrointestinal endoscopy: the fundamentals: John Wiley \& Sons; 2008.

14. Kutluturkan S, Gorgulu U, Fesci H, Karavelioglu A. The effects of providing pre-gastrointestinal endoscopy written educational material on patients' anxiety: A randomised controlled trial. Int J Nurs Stud. 2010;47(9):1066-73.

15. Hinkle JL, Cheever KH. Brunner \& Suddarth's textbook of medicalsurgical nursing: Lippincott Williams \& Wilkins; 2013.

16. Sargin M, Uluer MS, Aydogan E, Hanedan B, Tepe Mİ, Eryılmaz MA, et al. Anxiety Levels in Patients Undergoing Sedation for Elective Upper Gastrointestinal Endoscopy and Colonoscopy. Med Archiv. 2016;70(2):112.

17. Trevisani L, Sartori S, Putinati S, Gaudenzi P, Chiamenti C, Gilli G, et al. Assessment of anxiety levels in patients during diagnostic endoscopy. Recenti Prog Med. 2002;93(4):240-4.

18. Maguire D, Walsh J, Little C. The effect of information and behavioural training on endoscopy patients' clinical outcomes. Patient Educ Couns. 2004;54(1):61-5.

19. Orujlu S, Hemmati-Maslakpak M. Effect of nursing interventions on anxiety and vital signs in patients undergoing endoscopy: a randomized clinical trial study. J Clin Nurs Midwif. 2014;3(3):36-43.

20. Wani S, Muthusamy VR, Shaheen NJ, Yadlapati R, Wilson R, Abrams JA, et al. Development of quality indicators for endoscopic eradication therapies in Barrett's esophagus: the TREAT-BE (Treatment with Resection and Endoscopic Ablation Techniques for Barrett's Esophagus) Consortium. Gastrointestinal Endoscopy. 2017.

21. Arabul M, Kandemir A, Celik M, Torun S, Beyazit Y, Alper E, et al. Impact of video information before unsedated upper gastrointestinal endoscopy on patient satisfaction and anxiety: a prospective randomized trial. Prz Gastroenterol. 2013;8:44-9.

22. Hashemy S, Zakerimoghadam M. Comparative study of the effect of muscle relaxation and music therapy on anxiety level in patients waiting for cardiac catheterization. Iran $\mathrm{J}$ Cardiovasc Nurs. 2013;1(4):22-30.

23. El-Hassan H, McKeown K, Muller A. Clinical trial: music reduces 
anxiety levels in patients attending for endoscopy. Aliment Pharmacol Ther. 2009;(7)30:718-24.

24. Savas N. Gastrointestinal endoscopy in pregnancy. World J Gastroenterol: WJG. 2014;20(41):15241.

25. Wolf LL, Ibrahim R, Miao C, Muyco A, Hosseinipour MC, Shores C. Esophagogastroduodenoscopy in a public referral hospital in Lilongwe, Malawi: spectrum of disease and associated risk factors. World J Surg. 2012;36(5):1074-82.

26. Torabi M, Salavati M, Sarabi AG. Effect of foot reflexology massage and benson relaxation techniques on anxiety and physiological indexes of patients undergoing coronary heart angiography. Sci J Hamadan Nurs Midwifery Fac. 2012;20(1):63-73.

27. Triantafillidis JK, Merikas E, Nikolakis D, Papalois AE. Sedation in gastrointestinal endoscopy: current issues. World J Gastroenterol. 2013;19(4):463-81.

28. Rafieeyan Z, Azarbarzin M, Safaryfard S. The effect of music therapy on anxiety, pain, nausea and vital signs of caesarean section clients in Dr. Shariatee hospital of Esfahan in 2006. Med Sci J Islamic Azad Univ Tehran Med Branch. 2009;19(1):25-30.

29. Zarei B, Saifi T, Fazeli A, Khodadadi E, Namavar A. Evaluation of Antibacterial effects of marshmallow (Althaea officinalis) On four strains of bacteria. Intl J Agri Crop Sci. 2013;5(14):1571.

30. Booth FW, Roberts CK, Laye MJ. Lack of exercise is a major cause of chronic diseases. Compr Physiol. 2012.

31. Organization WH. Preventing chronic diseases: a vital investment. 2005. 2011

32. Tazakori Z ,Amani F, Karimollahi M. The effect of music therapy on patients' blood pressure in endoscopy unit in Bou-Ali hospital, Ardebil. Iran J Nurs Midwif Res. 2008;12(1).

33. Yoo JY, Hahm SK, Chun JY, Lee SH, Cho SH, Park JA. The effect of family member's attendance on relief of patient's discomfort during upper gastrointestinal endoscopy. Korean J Fam Med. 2008;29(1):139.

34. Sun WYL, Dang JT, Switzer NJ, de Gara C, Birch DW, Karmali S. The utility of routine esophagogastroduodenoscopy before laparoscopic Roux-en-Y gastric bypass. Surg Obes Relat Dis. 2017.

35. Hopewell S, Hirst A, Collins GS, Mallett S, Yu LM, Altman DG. Reporting of participant flow diagrams in published reports of randomized trials. Trials. 2011;12:253.

36. Khodayarifard M, Spielberger CD, Lavasani MG, Zardkhaneh SA. Psychometric properties of Farsi version of the Spielberger's state-trait anger expression inventory-2 (FSTAXI-2). Procedia Soc Behav Sci. 2013;82:325-9

37. Rudin D, Kiss A, Wetz R, Sottile V. Music in the endoscopy suite: a meta-analysis of randomized controlled studies. Endoscopy. 2007;39(06):507-10.

38. Eberhardt J, Wersch A, Schaik P, Cann P. Information, social support and anxiety before gastrointestinal endoscopy. Br J Health Psychol. 2006;(4)1:551-9.

39. Callaghan P, Chan HC. The effect of videotaped or written information on Chinese gastroscopy patients' clinical outcomes. Patient Educ Couns. 2007;42(3):225-30.

40. Seda P, VAN No, Mehmet YP, Van O, Gulfien MT. Effect of providing information to the patient about upper gastrointestinal endoscopy on the patient's perception, compliance and anxiety level associated with the procedure. Turk J Gastroenterol. 2011;22(1):10-7.

41. Salmore RG, Nelson JP. The effect of preprocedure teaching, relaxation instruction, and music on anxiety as measured by blood pressures in an outpatient gastrointestinal endoscopy laboratory. Gastroenterol Nurs. 2009;23(3):102-10. 